\title{
FREQUENCY OF HEPATITIS B AND C IN PATIENTS UNDERGOING CATARACT SURGERY IN A TERTIARY CARE EYE HOSPITAL
}

\author{
Summaya Khan, Aisha Rafique, Muhammad Azeem Khizer, Omar Zafar \\ Armed Forces Institute of Ophthalmology/National University of Medical Sciences (NUMS) Rawalpindi Pakistan
}

\begin{abstract}
Objective: To assess frequency of Hepatitis B and C infection in patients undergoing cataract surgery.

Study Design: Cross sectional study.

Place and Duration of Study: Armed Forces Institute of Ophthalmology, Rawalpindi, from Jan 2018 to Jan 2020.

Methodology: Pre operatively patients were subjected to detail ocular examination for cataract evaluation. Patient under 20 years of age, complicated cataract, uveitis, retinal detachment, previous history of ocular surgery or neurosurgery, treatment with systemic medication causing ocular side effects were excluded from study. Pre operatively hepatitis B and C screening was performed for all enrolled patients. The findings were recorded on data sheets and analyzed through statistical software system (SPSS) version 20.

Results: Out of 4671 patients, $35(0.74 \%)$ were positive for hepatitis B surface antigen (HBsAg) and $146(3.1 \%)$ were positive for hepatitis C antibody (HCVAb). Eight (22.8\%) females and $27(77.17 \%)$ males were positive for HBsAg. Fifty seven (39.04\%) females and 88 (60.96\%) males were found to be HCVAb positive. It clearly shows higher prevalence of hepatitis in males. Twenty three (65\%) of patient with hepatitis B virus and $80(54.8 \%)$ of patients with hepatitis $C$ virus had nuclear sclerosis cataract as compared to $51 \%$ of non-infected patients.

Conclusion: Screening of hepatitis B and C is mandatory in order to prevent health care associated hepatitis infection. There has been a role of inflammation due to hepatitis in development of cataract. Further studies may elaborate it vividly.
\end{abstract}

Keywords: Cataract surgery, hepatitis B, hepatitis C.

This is an Open Access article distributed under the terms of the Creative Commons Attribution License (http://creativecommons.org/licenses/by/4.0), which permits unrestricted use, distribution, and reproduction in any medium, provided the original work is properly cited.

\section{INTRODUCTION}

Liver is considered as metabolic power house of our body. Hepatitis is infection of liver causing inflammatory process leading to cirrhosis or hepatocellular carcinoma ${ }^{1}$. Viruses are considered as most common etiological agent of hepatitis. Other etiologies are alcohol, autoimmune and toxic hepatitis. Symptoms of viral hepatitis range from acute to chronic relentless disease ${ }^{2}$. One million people die of Hepatitis B virus (HBV) each year. Prevalence of hepatitis C $(\mathrm{HCV})$ is $3 \%$ globally. It is recognized as major cause of chronic liver disease progressing to malignant disease $^{3}$. There is arising incidence of hepatitis B and $\mathrm{C}$ in our country. According to some studies, $10 \%$ of Pakistani population is infected by HBV. Prevalence of $\mathrm{HCV}$ ranges from $4-10 \%$. Majority of infected patients die within 1-3 years. The

Correspondence: Dr Ayesha Rafique, Dept of Ophthalmology, Armed Forces Institute of Ophthalmology, Rawalpindi Pakistan Received: 22 Jul 2020; revised received: 14 Nov 2020; accepted: 20 Oct 2020 reason believed to be delayed access to diagnostic and therapeutic facilities ${ }^{4}$. There has been threefold increase in cases of hepatocellular carcinoma over last two decade in a tertiary care hospital of Pakistan ${ }^{5}$. Due to unavailability of preventive vaccine against $\mathrm{HCV}$, risk of acquiring infection should be addressed. These viral infections are transmitted primarily via blood and blood borne products 6 . In our country most people are unaware of hepatitis as this disease is highly prevalent in far flung areas with low literacy rate and inadequate medical facilities. Thus resulting in repeated admissions burdening inadvertently financial constraints ${ }^{7}$.

Oxidative stress induced by damaging liver cells due to hepatitis is considered to be responsible for extra hepatic manifestations such as renal dysfunction, encephalopathy and cardiovascular event ${ }^{8}$. Age related cataract is clouding of crystalline lens. It is the leading cause of blindness worldwide which ultimately requires sur- 
gery. Pathogenesis in development of age related cataract includes free radical formation and depletion of antioxidant reservoirs with advancing age $^{9}$. In contrast to normal elderly population, compromised metabolic system leading to increased oxidative stress in hepatitis may lead to early development of cataract. There is limited data suggesting $\mathrm{HBV} / \mathrm{HCV}$ as risk factor for cataract development. However, whether cataracts represent an extra-hepatic manifestation of viral hepatitis remains unclear ${ }^{10}$.

This study aims to assess frequency of $\mathrm{HBV} /$ HCV seropositive undergoing cataract surgery. This will raise awareness regarding prevention of acquiring infection due to per cutaneous exposure during cataract surgery. It will also help us to understand the role of hepatitis induced inflammation in cataract development.

\section{METHODOLOGY}

This cross sectional study was conducted in Armed forces institute of ophthalmology over a duration of two years from Jan 2018 to Jan 2020. After taking approval from institutional ethics review committee (254/ERC/AFIO dated 22 Jun 2020), 4671 patients visiting cataract clinic were included in the study using non probability consecutive sampling technique ${ }^{11}$. Pre-operatively, a detailed history was taken and information regarding comorbid conditions like ischemic heart disease, hypertension, diabetes mellitus, asthma, previous systemic infection and hepatitis were documented. Patients were then subjected to comprehensive ocular examination for cataract evaluation including visual acuity, anterior and posterior segment examination, intra ocular pressure measurement followed by biometry for intraocular lens (IOL) power calculation. Patients were investigated for blood sugar levels and hepatitis screening. They were evaluated byenzymelinked immunosorbent assay (ELISA) method for quantitative estimation of $\mathrm{HBsAg}$ and $\mathrm{HCV} \mathrm{Ab}{ }^{12}$. Ethical considerations like patient demographic data and their results were kept confidential.

Patients under 20 years of age, complicated cataract, uveitis, retinal detachment, previous history of ocular surgery or neurosurgery, treatment with systemic medication causing ocular side effects were excluded from study. All the patients were briefly described about the purpose of the study and informed written consent was taken prior to the inclusion in the study. The sample size was calculated by using WHO sample size calculator. Level of significance of $5 \%$, and power of test $80 \%$ was used in sample size calculation ${ }^{13}$. The findings were recorded on data sheets and analyzed by using statistical tools of analysis i.e. (SPSS) version 2.0.

\section{RESULTS}

This study comprised of 4671 patients, 181 (3.87\%) patients were found to be positive either for HBsAg or anti HCVAb. Thirty five $(0.74 \%)$ were positive for HBsAg and 146 (3.1\%) were positive for HCVAb. Eight (22.8\%) females and $27(77.17 \%)$ males were positive for HBsAg. Fifty seven $(39.04 \%)$ females and $88(60.96 \%)$ males were found to have HCVAb positive. It clearly shows higher prevalence of hepatitis in males (table).

Table: Descriptive statistics of seropositive patients.

\begin{tabular}{|c|c|}
\hline Characteristics & n $(\%)$ \\
\hline Total number of participants & $4671(100)$ \\
\hline $\begin{array}{l}\text { Hepatitis B, Virus/ Hepatitis C Virus } \\
\text { Positive }\end{array}$ & $181(3.87)$ \\
\hline \multicolumn{2}{|l|}{ Type of Hepatitis Markers } \\
\hline Hepatitis B Virus Positive & $35(0.74)$ \\
\hline Hepatitis C VirusPositive & $146(3.1)$ \\
\hline \multicolumn{2}{|l|}{ Age of Patients } \\
\hline $\begin{array}{l}\text { Mean age (Hepatitis B Virus } \\
\text { Positive) }\end{array}$ & $\begin{array}{c}63.35 \pm \\
8.87\end{array}$ \\
\hline $\begin{array}{l}\text { Mean age (Hepatitis C Virus } \\
\text { Positive) }\end{array}$ & $69.2 \pm 4.56$ \\
\hline \multicolumn{2}{|l|}{ Gender of Patients } \\
\hline Male (Hepatitis B Virus Positive) & $27(77.17)$ \\
\hline Female (Hepatitis B Virus Positive) & $8(22.8)$ \\
\hline Male (Hepatitis C Virus Positive) & $88(60.96)$ \\
\hline Female (Hepatitis C Virus Positive) & $57(57)$ \\
\hline \multicolumn{2}{|l|}{ Nuclear Sclerosis Cataract } \\
\hline Hepatitis B Virus Positive & $\begin{array}{l}23 \text { out of } \\
35(65)\end{array}$ \\
\hline Hepatitis C VirusPositive & $\begin{array}{l}80 \text { out of } \\
146(54.8)\end{array}$ \\
\hline
\end{tabular}


Mean age of seropositive patients at the time of presentation with symptoms of cataract was $63.3 \pm 8.87$ years while mean age of seronegative patients was $69.2 \pm 4.56$ years. Twenty three $(65 \%)$ of patients with $\mathrm{HBV}$ and $80(54.8 \%)$ of patients with HCV had nuclear sclerosis cataract as compared to $51 \%$ of non-infectious patients (figure).

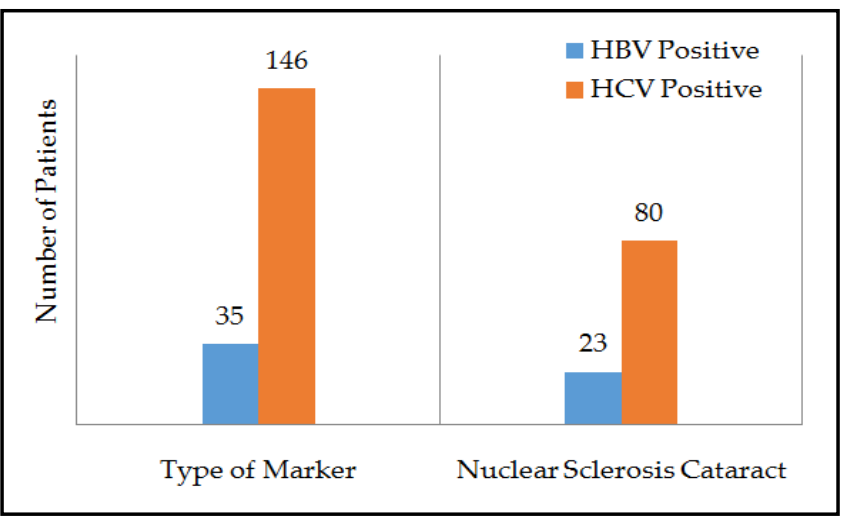

Figure: Statistics of seropositive patients.

\section{DISCUSSION}

This study shows prevalence of $3.87 \%$ of hepatitis in patients undergoing cataract surgery with a higher prevalence of hepatitis $C$ which is similar to study by Naem et al13. It implies strict screening for hepatitis serology should be carried out pre operatively in order to avoid exposure of infective agents to the operation theatre staff and surgeon $^{14}$. This is pertinent as there has been incidents of health care associated hepatitis transmission due to breached safety precautionary measures $^{15}$.

This study revealed higher prevalence of hepatitis C as compared to hepatitis B in overall sample size. It is in contrast to study by Park et al, conducted over Korean population where prevalence of hepatitis B is greater than hepatitis C. Higher prevalence of hepatitis $C$ in this study may be attributed to the fact that hepatitis $B$ vaccination has been introduced in extended program of immunization whereas there is no vaccine against hepatitis $C$ virus $^{16}$. Mean age of $\mathrm{HBV} / \mathrm{HCV}$ infected patient presenting with visually significant cataract is approximately 9 years earlier as compared to mean age at which uninfected patients presented. There are studies where such correlation between hepatitis and cataract has further been augmented by taking in account of chemical markers like Aspartate transaminase (AST) and Alanine aminotransferase (ALT) levels. These studies reveal that raised levels of these enzymes have positive correlation in the development of cataract owing to inflammation ${ }^{17}$.

This study showed higher prevalence of hepatitis in males as compared to females. This is comparable to study by Mansha et al ${ }^{18}$. Attributable cause can be social freedom and agility male relish in certain areas of Pakistan, so greater likelihood of contracting infection.

This study highlighted higher prevalence of nuclear sclerotic cataract in infected patients as compared to uninfected patients. It indicates that both HBV and HCV infection are significantly associated with age nuclear cataract. These findings are consistent with another study ${ }^{19}$. It implies that HBV or HCV infected patients ought to be be examined and vigilantly monitored for cataract development pertaining ocular health. Research studies have reflected the biological plausibility of lenticular opacification by HBV infection owing to increased fibroblasts activity leading to inflammatory fibrosis. It is indicated by AST and ALT levels which are the top predictors for substantial inflammation ${ }^{20}$. Increased oxidative stress due to induced hepatocellular damage, malfunctioning of metabolic machinery and accumulation of toxic metabolic waste products further supplemented by chronic inflammation jeopardize formation of cataract ${ }^{21}$. Oxidative stress leads to dysfunction of corneal endothelium. It results in exposure of lens to toxic inflammatory metabolites. Sartori et al, proposed that active viral hepatitis cause damage to endothelium ${ }^{22}$. There has been evidence of viral antigens in tears and aqueous humor of patients infected with active viral hepatitis ${ }^{23}$. It may be further worsened by dysfunctional endothelium. Furthermore, HBV infection is considered in pathogenesis of age-related macular degeneration and dry eye disease ${ }^{24}$. Compared to HBV, 
$\mathrm{HCV}$ is more sinister in etiology of posterior segment disease such as acute loss of vision and retinopathy ${ }^{25}$.

\section{CONCLUSION}

Screening for $\mathrm{HBV}$ and $\mathrm{HCV}$ is mandatory in every patient undergoing cataract surgery to prevent its transmission. Future prospective studies tasking to molecular and genetic mechanics will aid to illuminate correlation between hepatitis induced liver malfunction and relatively earlier development of age related ventricular pacification.

\section{CONFLICT OF INTEREST}

This study has no conflict of interest to be declared by any authors.

\section{REFERENCES}

1. Ringelhan M, McKeating JA, Protzer U. Viral hepatitis and liver cancer [published correction appears. Philos Trans R Soc Lond B Biol Sci 2018; 373(1737): 20160274-78.

2. Szabó E, Páska C, Novák PK, Schaff Z, Kiss A. Similarities and differences in hepatitis $B$ and $C$ virus induced hepatocarcinogenesis. Pathol Oncol Res 2004; 10(1): 5-11.

3. Si J, Yu C, Guo Y, Bian Z, Meng R, Yang L, et al. Chronic hepatitis $B$ virus infection and total and cause-specific mortality: a prospective cohort study of 0.5 million people. BMJ Open 2019; 9(4): e027696-98.

4. Al Kanaani Z, Mahmud S, Kouyoumjian SP, Abu-Raddad LJ. The epidemiology of hepatitis $C$ virus in Pakistan: systematic review and meta-analyses. $R$ Soc Open Sci 2018; 5(4): 180257-60.

5. Butt AS, Abbas Z, Jafri W. Hepatocellular carcinoma in pakistan: where do we stand?. Hepat Mon 2012; 12(10HCC): e6023-25.

6. Konerman MA, Lok AS. Hepatitis $C$ treatment and barriers to eradication. Clin Transl Gastroenterol 2016; 7(9): e193-95.

7. Ali SA, Donahue RM, Qureshi H, Vermund SH. Hepatitis B and hepatitis $\mathrm{C}$ in Pakistan: prevalence and risk factors. Int J Infect Dis 2009; 13(1): 9-19.

8. Cacoub P, Comarmond C, Domont F, Savey L, Desbois AC, Saadoun D. Extrahepatic manifestations of chronic hepatitis C virus infection. Ther Adv Infect Dis 2016; 3(1): 3-14.

9. Nizami AA, Gulani AC. Cataract. [Updated 2019 Dec 2]. In: Stat Pearls [Internet]. Treasure Island (FL): StatPearls Publishing; 2020. Available from: https://www.ncbi.nlm.nih.gov/books/ NBK539699/.
10. Beebe DC, Holekamp NM. Oxidative damage and the prevention of age-related cataracts. Ophthalmic Res 2010; 44(3): 155-65.

11. Tahir MA, Cheema A, Tareen S. Frequency of Hepatitis-B and C in patients undergoing cataract surgery in a tertiary care Centre. Pak J Med Sci 2015; 31(4): 895-98.

12. Kim SH. ELISA for Quantitative Determination of Hepatitis B Virus Surface Antigen. Immune Netw 2017; 17(6): 451-59.

13. Naeem SS, Siddiqui EU, Kazi AN, Abdullah FE, Adhi I. Prevalence of Hepatitis ' $\mathrm{B}$ ' and Hepatitis ' $\mathrm{C}$ ' among preoperative cataract patients in Karachi. BMC Res Notes 2012; 5(1): 492-95.

14. Venkataiah Y, Lakshmi VV, Sreelakshmi G. Importance of Screening for HBSAG \& HIV in cataract surgery cases. Int J Recent Sci Res 2015: 6(7); 5268-71.

15. Riaz S, Khan MT, Mahmood K, Akhtar S. Frequency of hepatitis $\mathrm{b} \& \mathrm{c}$ in previously unscreened patients admitted for elective cataract surgery. Ophthalmol Update 2016; 14(4): 128-30.

16. Hepatitis-B-Expanded Program on Immunization, Pakistan [Internet]. Epi.gov.pk. 2020 [cited 29 June 2020]. Available from: http:/ /www.epi.gov.pk/vaccine-preventablediseases/hepatitis-b/.

17. Park S, Choi N. Hepatitis virus infection and age-related cataract. Sci Rep 2017; 7(1): 13089-92.

18. Mansha M, Azhar F, Afzal F, Shahbaz M, Mustafa A. Prevalence of hepatitis $B$ and $C$ among cataract surgery patients in avicenna hospital Lahore. Pak J Med Health Sci 2019; 13(4): 876-877.

19. Paridon B. Association Between HBV, HCV and Age-related cataracts-infectious disease advisor [Internet]. Infectious Disease Advisor. 2020 [cited 29 June 2020]. Available from: https:// www.infectiousdiseaseadvisor.com/home/topics/gi-illness/ hepatitis/association-between-hbv-hcv-and-age-relatedcataracts/

20. International Agency for Research on Cancer. GLOBOCAN cancer fact sheets: liver cancers. Available from: http:// globocan.iarc.fr/old/FactSheets/ cancers/liver-new.asp

21. Klein BE, Klein R, Lee KE, Knudtson MD, Tsai MY. Markers of inflammation, vascular endothelial dysfunction, and age-related cataract.c Am J Ophthalmol 2006; 141(1): 116-22.

22. Sartori MT, Bilora F, Zanon E, Varvarikis C, Saggiorato G, Campagnolo E, et al. Endothelial dysfunction in haemophilia patients. Haemophilia 2008; 14(5): 1055-62.

23. Feucht HH, Zöllner B, Schröter M, Altrogge H, Laufs R. Tear fluid of hepatitis $C$ virus carriers could be infectious. J Clin Microbiol 1995; 33(8): 2202-03.

24. Tien PT, Lin CJ, Tsai YY, Chen SS, Hwang DK, Hsin Muo C, et al. Relationship between uveitis, different types of viral hepatitis, and liver cirrhosis: A 12-Year Nationwide PopulationBased Cohort Study. Retina 2016; 36(12): 2391-98.

25. Guidelines for the prevention, care and treatment of persons with chronic hepatitis B infection [Internet]. World Health Organization. 2020 [cited 4 July 2020]. Available from: https:// www.who.int/hiv/pub/hepatitis/hepatitis-b-guidelines/en/. 